\title{
DESDOBRAMENTOS DA EDUCAÇÃO PERMANENTE EM SAÚDE NO MUNICÍPIO DE VITÓRIA, ESPÍRITO SANTO
}

\author{
RAMIFICATIONS OF CONTINUING EDUCATION IN HEALTH IN VITÓRIA, STATE OF ESPÍRITO SANTO
}

\author{
Elzimar Evangelista Peixoto Pinto ${ }^{1}$ \\ Maristela Dalbello de Araújo ${ }^{2}$ \\ Silvia Matumoto ${ }^{3}$ \\ Ângela Aparecida Capozzolo ${ }^{4}$ \\ Maria Rosa Logiodice Cardoso ${ }^{5}$ \\ Silvana Martins Mishima ${ }^{6}$
}

Resumo Este artigo tem como objetivo discutir os desdobramentos do processo de formação de facilitadores e o trabalho de efetivação de 'rodas' de Educação Permanente em Saúde (EPS) em unidades de serviços de saúde no município de Vitória, Espírito Santo, cenário selecionado a partir de mapeamento dentre várias experiências de EPS em andamento no país. Adota os pressupostos metodológicos sugeridos pela cartografia para produção e análise dos dados, utilizando variadas estratégias, como observação participante, entrevistas individuais e coletivas com os profissionais e usuários. Verifica que o termo EPS admite várias concepções: movimento que coloca o trabalho em análise, visando a definir prioridades locais que promovam a reorganização dos espaços de produção de saúde; estratégia de formação dos profissionais de saúde em um processo constante de subjetivação, como estratégia de gestão, na medida em que possibilita reorganizar a gestão a partir da problematização do trabalho. Verifica a existência de 59 Rodas de EPS distribuídas em 25 serviços de saúde, com a presença de dois facilitadores em cada uma. Conclui que, nesse cenário, as várias concepções disputaram espaço e produziram efeitos, especialmente perceptíveis na mudança da forma como os profissionais compreendem o processo educativo e a sua interação com o cotidiano do trabalho.

Palavras-chave educação; saúde; recursos humanos; políticas públicas.
Abstract This article aims to discuss the ramifications of the process of training of facilitators and materializing Permanent Education in Health (PEH) 'rounds' in health services units in Vitória, state of Espírito Santo, the scenario which was selected to map several PEH experiments already underway in the country. It adopts the methodological assumptions suggested by mapping to produce and analyze data, using various strategies such as participant observation and individual and collective interviews with professionals and users. It was noted that the PEH expression encompasses several concepts: movement that places the work under review in order to define local priorities that drive the reorganization of the health production spaces; strategy to train health professionals in a constant process of subjectification, a management strategy, as it enables management to be reorganized based on the questioning of the work. It singled out 59 PEH Rounds spread among 25 health services, with the presence of two facilitators in each. It concludes that, in this scenario, the various conceptions competed for space and produced effects that were particularly noticeable in changing the way the professionals perceive the educational process and its interaction with daily work.

Keywords education; health; human resources; public policies. 


\section{Introdução}

O presente artigo apresenta parte dos resultados da pesquisa "Avaliação das experiências de Educação Permanente em Saúde, desencadeadas a partir da formação a distância de tutores e facilitadores no Brasil", referente ao cenário do município de Vitória, Espírito Santo. A pesquisa recebeu financiamento do CNPq através de edital conjunto com o Ministério da Saúde, inserindo-se na Linha de Apoio Gestão da Educação em Saúde, com foco nas experiências e estratégias utilizadas para a educação de trabalhadores de saúde, baseadas nas concepções teórico-metodológicas da Educação Permanente em Saúde (EPS) e seu impacto nas práticas de saúde.

No contexto da Reforma Sanitária e implantação do Sistema Único de Saúde (SUS), a área de 'recursos humanos' em saúde passou a ter crescente importância na construção do novo modelo de sistema de saúde, constituindo-se em um dos desafios colocados, na atualidade, aos gestores da saúde. Investir nessa área implica um esforço de reflexão e intervenção no sentido da qualificação da força de trabalho em saúde, na direção da estruturação de um modelo de atenção que contribua para a qualificação da vida dos usuários.

Assim, os processos educativos passaram a ter maior visibilidade, tanto no que concerne à sua importância quanto à necessidade de novos aportes teóricos que municiem os profissionais responsáveis por dar materialidade ao novo modelo assistencial, fazendo-se presentes preocupações no que diz respeito, por exemplo, à formulação e desenvolvimento de processos educativos na linha da educação permanente em saúde, formação dos profissionais de saúde articulada ao processo de trabalho.

Considerando que as práticas de saúde são transformadas a partir dos seus atores, qualquer alteração no eixo dessas práticas passa, necessariamente, por mudanças no modus operandi dos profissionais de saúde. Assim, os projetos de EPS que delimitam os processos educacionais, no âmbito dos profissionais de saúde, tomam um novo impulso, na medida em que colocam esses processos no centro da redefinição das práticas.

Segundo Motta (1998), o termo educação permanente em saúde, difundido pela Organização Pan-Americana de Saúde (Opas), a partir dos anos de 1980, teria como referência uma estratégia de reestruturação e desenvolvimento dos serviços, a partir de uma análise dos determinantes sociais e econômicos, baseada na transformação de valores e conceitos dos profissionais, visto que propõe transformá-los em sujeitos, colocando-os no centro do processo de ensino/aprendizagem.

Ainda segundo o autor, a proposta de educação permanente em saúde fundamenta-se em algumas premissas básicas: a educação é um processo contínuo e dinâmico; todo grupo social é educativo; a educação é um processo ordenador do pensamento; o conhecimento se origina das necessi- 
dades ou problemas sociais dentro de um projeto histórico; o projeto de educação permanente deve ser participativo desde o planejamento, execução, acompanhamento e avaliação, bem como deve ser flexível, pois comporta retificações e ajustes no processo (Motta, 1998).

Essa concepção problematiza as capacitações tradicionais organizadas de modo vertical que produziam poucas modificações na prática dos trabalhadores de saúde. Reconhece a importância dos processos de qualificação a partir das necessidades dos trabalhadores em seus diferentes contextos, bem como a necessidade de dialogar com seus conhecimentos prévios. Concebe ainda que o homem está em permanente formação e, em suas relações no cotidiano, produz conhecimento e sabedoria, fatores que transformam sua maneira de conduzir a vida e o trabalho (Ceccim; Feurwerker, 2004).

O Brasil implantou a Política Nacional de Educação Permanente em Saúde em fevereiro de 2004, por meio da Portaria GM n. ${ }^{\circ}$ 198/2004 (Brasil, 2004a) como uma estratégia do SUS para a formação e desenvolvimento dos trabalhadores da saúde, propondo mudanças nas práticas de educação na saúde, de modo que os próprios trabalhadores, em seu coletivo local, possam contribuir e conquistar capacidade de se assumirem como coautores do processo de formação, ao mesmo tempo em que criam novos modos de produzir saúde, sua gestão e instituições de saúde.

Assim a EPS se estrutura na construção coletiva de práticas inovadoras em saúde para efetivar a atenção integral mediante a satisfação das necessidades de saúde das populações, tomando como referencial pedagógico a aprendizagem significativa e, como estratégia de implementação, a gestão democrática (Brasil, 2004b).

Para a condução desta política, o Ministério da Saúde estimulou a implantação em todo país dos Polos de Educação Permanente em Saúde, instâncias de gestão da política. Os polos apresentavam

uma composição embasada no 'quadrilátero' configurado por gestores estaduais e municipais de saúde, formadores contemplando instituições com cursos para os trabalhadores da saúde; serviços de saúde representados pelos trabalhadores da área, e pelo controle social ou movimentos sociais de participação no sistema de saúde (Nicoletto et al., 2009, p. 2009).

Além disso, é possível destacar dos textos divulgados como parâmetros da Política Nacional de Educação Permanente em Saúde (Brasil, 2005) que o trabalho é a categoria central e referência principal dessa proposta, pois implica a formação de agentes inseridos nesse processo, tomado, como eixo norteador, donde se derivam os problemas para os quais se buscam soluções. Trata-se, portanto, de reconhecer o caráter educativo do próprio trabalho e aproveitar as oportunidades educativas proporcionadas pela 
organização, pelo desenvolvimento e pela operação dos serviços de saúde. Além disso, esse projeto exige que os conflitos presentes nas práticas de saúde se manifestem plenamente e as estratégias pedagógicas possam estimular e facilitar a discussão e apropriação de conhecimentos e práticas pelos agentes do trabalho inseridos nas instituições. Ceccim (2005) sintetiza estas questões ao afirmar que a EPS é uma ação pedagógica que, tomando como foco o cotidiano do trabalho, possibilita processos de autoanálise, colocando em roda diferentes atores, neste processo, onde todos podem assumir um papel proativo na condução dos sistemas locais de saúde.

Em 2007, num processo de revisão da portaria n. ${ }^{\circ}$ 198/2004, é publicada a portaria GM/MS n. ${ }^{\circ} 1996$, de 20 de agosto de 2007, sustentada pelos mesmos princípios e premissas, mas oferecendo diretrizes atuais para a implementação da Política Nacional de Educação Permanente em Saúde (Brasil, 2007), com o estabelecimento das Comissões de Integração Ensino-Serviço (Cies), como instâncias para a negociação dos processos de EPS nas diferentes locorregiões do país.

Pensar os processos educacionais no interior dos serviços de saúde passa a se refletir criticamente sobre as práticas de saúde e as relações entre os sujeitos nelas envolvidos. Nesse sentido, é preciso pensar a reprodução/transformação dessas relações e práticas sociais, em um mundo que passa por transformações profundas, quer pela crise do modelo de racionalidade, que até então orientou o desenvolvimento das ciências, quer pelo próprio desenvolvimento tecnológico, que reestrutura as formas de organização do trabalho e nos impõe repensar a relação entre educação e trabalho (Santos, 2000).

Dentre as estratégias para desencadear o processo de educação permanente no SUS, realizou-se o processo de formação de facilitadores de educação permanente em saúde, por meio da organização e oferta do Curso de Formação de Facilitadores de Educação Permanente em Saúde. O curso foi uma responsabilidade compartilhada entre o Ministério da Saúde, por meio do Departamento de Gestão da Educação na Saúde (Deges)/Secretaria de Gestão do Trabalho e da Educação na Saúde (SGTES) e da Escola Nacional de Saúde Pública Sergio Arouca (Ensp)/Fundação Oswaldo Cruz (Fiocruz). O curso, oferecido na modalidade de Educação a Distância, com encontros presenciais, é composto por quatro unidades de aprendizagem: Integradora; Trabalho e relações na produção do cuidado em saúde; Práticas educativas no cotidiano do trabalho em saúde; e Análise do contexto de gestão e das práticas em saúde (Brasil, 2005).

Considerando este conjunto de aspectos, esta investigação operou com o conceito Educação Permanente em Saúde como 'colocar o trabalho em análise', por meio do envolvimento pessoal e coletivo de trabalhadores de saúde, e, pelo movimento analítico, procuramos eleger prioridades locais que promovam a reorganização dos espaços de produção de saúde. A EPS é 
utilizada como estratégia de formação dos profissionais de saúde, na perspectiva da formação técnica intimamente vinculada à formação dos sujeitos que operam os fazeres em saúde, num processo constante de subjetivação. Educação Permanente em Saúde também é entendida como estratégia de gestão, na medida em que possibilita reorganizar a gestão dos serviços e sistemas de saúde a partir da problematização do trabalho, processo permeado pela tensão decorrente da diversidade de interesses das instâncias da gestão, dos trabalhadores e da população.

Nesse sentido, passados quatro anos de implantação da política de EPS por parte do Ministério, fez-se necessário olhar os movimentos que foram desencadeados por tais dispositivos em várias partes do país. É com essa motivação que um grupo de pesquisadores vem investigando e reunindo insumos que possam contribuir para avaliar os limites e possibilidades de uma política. Como parte dessa grande tarefa, o objetivo deste artigo é apresentar e discutir os desdobramentos do processo de formação de facilitadores de Educação Permanente em Saúde e o trabalho de efetivação de 'rodas' de EPS em unidades de serviços de saúde no município de Vitória, no Espírito Santo.

\section{Método}

Vitória foi selecionada como um dos cenários da pesquisa a partir de mapeamento, dentre várias experiências de EPS realizadas e/ou em andamento no país, após a instituição da Política Nacional de Educação Permanente em Saúde (Brasil, 2004a e b). A escolha se deu por se tratar de um município que historicamente tem investido na formação e qualificação dos trabalhadores de saúde e também pelo interesse e envolvimento de atores locais com a implantação da EPS, desde sua proposição pelo Ministério da Saúde, inclusive com a participação de alguns desses atores como pesquisadores do projeto de pesquisa que originou este artigo.

Historicamente, o movimento científico se desenvolveu baseado na busca da neutralidade e da racionalidade do pesquisador frente ao seu objeto de pesquisa, entretanto consideramos a necessidade de recuperar a subjetividade e a integralidade dos sujeitos, principalmente quando percebemos que o pesquisador afeta e é afetado pelo que se debruça como questionamento. Advogamos esse campo de interferência, porém isso não significa ausência de rigor. Assim, estivemos atentas à análise de nossa implicação com o campo e abertas às sensações e afetos que ele suscita. Entendemos que não existe método de pesquisa neutro e que as escolhas metodológicas estão ligadas a opções teóricas e políticas assumidas pelo pesquisador (Dalbello-Araújo, 2008a).

Nesse sentido, afirmamos nossa proposta ética e política, ao abordar o tema da Educação Permanente em Saúde, observando seus desdobramentos 
nos diferentes cenários investigados, por meio de uma postura cartográfica adequada para o estudo da subjetividade e dos processos de produção da vida cotidiana (Kastrup, 2007).

Nesse contexto, cartografar é, portanto, um ato de sensibilidade conectado aos movimentos de construção e desconstrução da vida cotidiana, aos processos de produção de subjetividade, às conexões e agenciamentos sociais, enfim, ao caráter dinâmico e mutante de nossa vida coletiva. De acordo com essa postura, as paisagens psicossociais são mutáveis, havendo uma processualidade na sua construção passível de ser cartografada (Rolnik, 2006).

Da mesma forma, compreendemos que os territórios/cenários que acompanhamos são dinâmicos, em permanente mudança. Propusemo-nos, então, registrar cinco marcadores dessas mudanças em nossa cartografia, que descrevem, de forma geral: a adoção da Política Nacional de Educação Permanente em Saúde pelo município, o seu desenvolvimento por meio das 'rodas', as dificuldades para sua sustentação e o seu encerramento.

Os dados foram produzidos e analisados no período de dezembro de 2007 a dezembro de 2008. Foi possível obter informações acerca da estrutura, equipe de trabalhadores, serviços ofertados, organização da unidade, processo de trabalho das equipes e forma como operacionalizavam a EPS. Essa aproximação do campo apontou indícios de diversidade na concepção de EPS e também sugeriu a necessidade de aprofundar estudos nesse cenário.

O minucioso mapeamento das unidades de saúde de Vitória pôde identificar quais operavam em EPS e tinham uma prática sistemática de 'rodas' e outras que não utilizavam as 'rodas' de EPS em seu cotidiano. Com o intuito de abarcar tal diversidade realizamos movimentos variados de exploração do campo, como: visitas a sete unidades básicas de saúde (UBS) e ao Centro de Referência em DST/Aids. Nessas visitas, realizamos observações participantes e 12 entrevistas com trabalhadores de saúde e gestores locais, ainda participamos de reunião sobre o tema educação permanente e de uma 'roda' de EPS em uma das unidades. As entrevistas, de caráter semiestruturado, procuraram abordar as concepções de EPS e os efeitos observados pelos profissionais na sua prática cotidiana.

Nessa etapa, os sujeitos da pesquisa foram os membros das equipes, de categorias diversas, gestores locais e facilitadores de EPS. Os dados foram registrados em diários de campo ou gravados em áudio. A análise preliminar dos dados7 apontou a necessidade de aprofundar a discussão com técnicos responsáveis pela implantação e acompanhamento das 'rodas' de EPS no município. Com essa finalidade, realizamos uma entrevista coletiva em agosto de 2008, com a presença de dez facilitadores.

Em todas as etapas da pesquisa, os participantes assinaram o Termo de Consentimento Livre e Esclarecido, conforme regulamenta o Conselho Nacional de Saúde - Resolução n. ${ }^{\circ}$ 196/96. O projeto foi aprovado pelo Comitê 
de Ética em Pesquisa da Escola de Enfermagem de Ribeirão Preto da Universidade de São Paulo, sob o n. ${ }^{\circ}$ 0748/2007.

\section{Discussão sobre o cenário e seus desdobramentos}

Vitória, capital do Estado do Espírito Santo, possui uma população de 291.941 habitantes, distribuídos em uma área geográfica de $89 \mathrm{~km}^{2}$.

A partir de 1990, o município passou por vários processos de organização do sistema de saúde, divisão do território em seis regiões, elaboração do diagnóstico situacional em saúde; apropriação dos territórios pelas unidades de saúde; implantação da Saúde da Família como estratégia para a organização da atenção primária; implantação dos conselhos locais de saúde; e a construção do Sistema Integrado de Serviços de Saúde.

Atualmente, o sistema conta com ampla rede de serviços de saúde: 28 unidades básicas de saúde; dois pronto-atendimentos; uma policlínica; um centro de especialidades odontológicas (CEO); um centro municipal de especialidades; seis centros de referência: atendimento ao idoso (Crai), atenção psicossocial (Caps), prevenção de tratamento aos toxicômanos (CPTT), promoção e recuperação física com 11 módulos de serviço de orientação ao exercício (SOE), Controle de Zoonoses (CCZ) e Tratamento de DST/Aids, além de serviços próprios de apoio com laboratório de análises clínicas, de manipulação de medicamentos fitoterápicos, central de ambulâncias e central municipal de agendamento de especialidades. A assistência hospitalar é mantida por meio de convênios.

A implantação da Estratégia Saúde da Família (ESF) teve início em 1998 pelas regiões com índices epidemiológicos desfavoráveis e, posteriormente, foi estendida para todo o município. Com a expansão e a nova estratégia, as equipes encontraram dificuldades em garantir a integralidade da assistência e em resolver problemas que demandam atenção secundária e terciária (Passamani, 2008).

Nesse ínterim, houve ampliação da cobertura de ESF de 59,33\%, em 2006, para $69,70 \%$, em 2008, e desde então o município vem realizando concurso público para eliminar os contratos temporários de trabalho que, em 2006, representavam aproximadamente $70 \%$ dos profissionais de saúde (Vitória, 2006).

O município também investiu na inclusão de outros profissionais, como psicólogo, educador físico, farmacêutico, assistente social e pediatra, como equipe de apoio às equipes básicas da ESF, buscando maior resolubilidade das ações de saúde (Brasil, 2005).

A implantação da ESF impôs um novo desafio - a capacitação dos trabalhadores de saúde. Assumir a saúde da família como diretriz significa rever as relações entre profissionais de saúde e população, pois se espera da 
equipe de saúde da família prática humanizada e resolutiva, envolvendo ações de promoção, prevenção, tratamento e reabilitação em saúde (Cardoso; Murad; Bof; 2005).

Dessa forma, na tentativa de responder às lacunas de formação, principalmente dos médicos, visando à melhoria das suas competências clínicas, em 2002, a Secretaria Municipal de Saúde (Semus) empreendeu várias iniciativas para qualificação dos trabalhadores e formação de educadores, como o projeto "Educação permanente para os profissionais de nível superior das equipes de saúde da família do município de Vitória", denominado Programa de Educação Permanente (PEP). Vale ressaltar que, ainda que fosse assim denominado, apresentava diferenças conceituais com o que viria a se firmar como a política de Educação Permanente em Saúde.

A equipe de educadores do PEP encontrava dificuldades para obter resultados satisfatórios devido à grande rotatividade de profissionais, decorrente dos vínculos temporários de trabalho. Apesar dos esforços, as ações de treina-mento não resultavam em impacto positivo nos indicadores de saúde. A prática do PEP baseava-se no 'treinamento' para a categoria médico de família, o que levou as demais categorias a reivindicarem espaços semelhantes.

Em um segundo momento, visando romper com a lógica das divisões por categorias profissionais, o PEP passou a ser desenvolvido por meio de grupos interdisciplinares, agrupados por região de saúde. Assim, reuniam-se com os educadores do PEP os profissionais médicos, assistentes sociais, psicólogos, farmacêuticos, enfermeiros e coordenadores de unidade de saúde para juntos discutirem temas de relevância para o seu território. Nesse momento, já havia o reconhecimento do trabalho como um espaço de formação, focava-se nos aspectos técnicos das ações e buscava-se desenvolver o trabalho em equipe.

No entanto, as atividades educativas eram propostas a partir de indicadores do município, desconectadas das realidades locorregionais e com pouco envolvimento das equipes de saúde das UBS. No entanto, é inegável que a capacitação assim estruturada trazia conforto aos profissionais educadores no desempenho dessas atividades.

Em 2004, o Ministério da Saúde instituiu a Política Nacional de Educação Permanente em Saúde (Brasil, 2004) e, em parceria com a Escola Nacional de Saúde Pública Sergio Arouca (Ensp) e com a Fundação Oswaldo Cruz (Fiocruz), realizou o Curso de facilitadores em Educação Permanente em Saúde. Dois profissionais da Secretaria Municipal de Saúde que atuavam no então Núcleo de Educação em Saúde (NES), hoje Gerência de Formação e Desenvolvimento em Saúde (GFDS), formaram-se tutores e outros 21 técnicos da rede básica e do nível central foram selecionados para participar do Curso de Facilitadores em Educação Permanente em Saúde (Brasil, 2005).

Como efeito dessa movimentação, houve uma grande demanda de interessados na formação como facilitadores de EPS, dentre eles os demais 
técnicos do GFDS e os diretores das unidades de saúde. Havia o entendimento de que a proposta do Ministério da Saúde de EPS apresentava diferenças em relação ao que era desenvolvido pelo PEP do município.

Diante de tal demanda e como produto do próprio Curso de Formação de Facilitadores de EPS, foi realizado um curso de extensão em parceria com a Universidade Federal do Espírito Santo (Ufes), “Refletindo sobre o trabalho em saúde", possibilitando a formação de mais 83 trabalhadores de saúde como facilitadores de educação permanente. O curso utilizou metodologias ativas e material didático do Curso de Formação de Facilitadores de EPS (Dalbello-Araújo; Peixoto, 2005).

Em 2006, foi realizado o II Curso de Formação de Facilitadores em EPS em parceria com a Ensp/Fiocruz, formando novo grupo de tutores e facilitadores. No conjunto das iniciativas MS/Ensp/Fiocruz e com a parceria Ufes/PMV, entre o ano de 2005 e 2008, aproximadamente 150 profissionais do município concluíram o curso de Formação de Facilitadores de Educação Permanente em Saúde.

\section{Educação Permanente em Saúde: várias concepções e efeitos de transformação nos facilitadores}

Para os facilitadores entrevistados, o contato com o material didático do Curso de Formação de Facilitadores de Educação Permanente em Saúde foi importante, tanto pela síntese dos conteúdos como pela legitimação de pontos de vista prévios. Essa afirmação é verdadeira, independentemente do modo de inserção, ou da forma como se deu a formação (Dalbello-Araújo, 2008b).

A EPS chegou à rede de serviços com a chancela do governo e com legitimidade inquestionável, trazendo alívio aos profissionais que se sentiram reforçados em seu modo de pensar: “Então, pra mim, foi um acalanto pra alma, porque eu estava fazendo uma coisa que é uma diretriz maior"(Entrevista coletiva, Facilitadores).

Muitos relataram surpresa e satisfação com a leitura do material e com a forma como foi ele foi trabalhado durante o curso. Afirmaram que o momento presencial do Curso de Facilitadores vivenciado na cidade do Rio de Janeiro foi totalmente novo e diferente do que estavam habituados a nomear como educação permanente: “A gente não conseguia ter uma dimensão do que estava sendo proposto. E eu acho que a clareza e a magnitude da proposta a gente conheceu no curso" (Entrevista coletiva, Facilitadores).

As avaliações dos desdobramentos do curso foram diversas. Alguns mencionaram que ele ajudou em vários aspectos e não apenas em educação (stricto sensu); outros referiram que essa forma de ver o mundo ajudou a compreender melhor as pessoas e os processos grupais: “O curso ajudou a gente 
a entender um pouco melhor como que se davam estas relações, os conflitos... eu achei assim, fantástico! Adorei" (Entrevista coletiva, Facilitadores).

As mudanças pessoais ocorridas após o curso também são destacadas:

Aquele momento no Rio foi um divisor de águas na minha vida pública, de profissional... Eu passei a enxergar uma outra forma de saúde, trabalho em unidade. Isso mudou muito a concepção em relação a como trabalhar em unidade de saúde (Entrevista coletiva, Facilitadores).

Outros desdobramentos da EPS foram apontados, entre eles a própria concepção do que se compreende por educação.

Hoje, as discussões em relação à formação dos profissionais na secretaria saíram de um lugar de formação, num modelo tradicional, pra uma outra coisa, com uma outra metodologia [...]. Agora, quando a gente vai discutir esta questão de aperfeiçoamento, capacitação, a gente sempre trabalha de forma que o ativador de mudança nos forneceu e que o facilitador também nos trouxe [...] então eu acho que isso é que é fundamental (Entrevista coletiva, Facilitadores).

\section{As 'rodas' de EPS: implantação}

A implantação dos espaços coletivos denominados 'rodas de Educação Permanente' iniciou-se em 2005. As 'rodas' ou 'rodas de EPS' foram definidas como espaços democráticos de discussão entre profissionais da equipe de saúde local, gestores, usuários e instituições de ensino. Objetivavam contribuir para a transformação das práticas de saúde, fortalecendo o trabalho em equipe, integrando saberes e profissionais, construindo, assim, soluções coletivamente. Tal espaço também se propunha a estabelecer a gestão participativa, afirmando a indissociabilidade formação/gestão/atenção.

A implantação das 'rodas' foi priorizada para as UBS que atuavam de acordo com a ESF, em decorrência das características favorecedoras e das necessidades das UBS/ESF, tais como: profissionais com carga horária de oito horas diárias; grande demanda da população por serviços após visitas dos profissionais de saúde; e o interesse da própria Semus em fortalecer a nova organização do setor saúde com a ESF.

Para dar início às 'rodas' de EPS, formaram-se duplas de facilitadores que pudessem se apoiar mutuamente e efetivar a inovação. No total, havia 23 facilitadores agrupados organizacionalmente sob a GFDS. No ano seguinte, 25 serviços de saúde da rede municipal realizavam 'rodas' de Educação Permanente de maneira sistemática e frequente. 
As 'rodas' de EPS tinham como objetivo expresso a discussão de temas relacionados com a organização e aperfeiçoamento do processo de trabalho nas UBS identificados pelo conjunto de trabalhadores locais. Os mais comumente referidos foram: formação de grupos de adolescentes nas unidades; organização do fluxo do Hiperdia; organização da assistência à população de rua; criação de projetos locais de promoção de saúde; organização da assistência aos diversos grupos (criança, mulher, idoso etc.); fluxo de atendimento da Odontologia; adequação do espaço físico dos US, entre outros. Assim, os trabalhadores discutiam o próprio processo de trabalho, servindo as 'rodas' como espaço de formação, com temas emergentes das necessidades do próprio grupo. Ao mesmo tempo, os facilitadores propunham temas, como: acolhimento; gestão participativa e clínica ampliada; princípios do SUS; estratégia de saúde da família; controle social; carta de direitos dos usuários; e pacto pela vida, abordados por meio de metodologias ativas de aprendizagem.

Destaca-se um direcionamento sutil na medida em que os temas propostos pelos facilitadores se apresentavam como novidades para o campo da saúde e, dessa forma, despertavam a curiosidade dos profissionais, mesmo que prioridades locais não fossem contempladas. Ou seja, mantém-se a lógica em que alguém externo traz 'as novidades' e os profissionais e usuários conservam a posição de espera passiva, denotando um movimento contrário ao proposto pela EPS. Explicitam-se, também, as tensões do cotidiano das 'rodas', que, como território de práticas de saúde, constituem-se como espaço de disputas para definição, no caso, dos temas a serem abordados que, em última instância, expressam interesses e projetos dos sujeitos envolvidos e constroem práticas e políticas de saúde. As 'rodas' estabelecem espaços de explicitação dessas diferenças, tornando-se necessário processar as pactuações. No entanto, devido à diversidade das unidades de saúde, de suas equipes e dos facilitadores responsáveis por provocar o funcionamento das 'rodas', não descartamos a possibilidade de haver efetivação de práticas por imposição, sem negociações (Merhy, 2002; Merhy; Feurwerker; Ceccim, 2006).

Constatamos grande esforço e investimentos na implantação das 'rodas' e também passos importantes na direção da gestão compartilhada proposta pela EPS, embora as lógicas instituídas ainda predominem, reproduzindo, por vezes, relações hierárquicas.

\section{Dificuldades enfrentadas pelos facilitadores}

Não há dúvida de que uma iniciativa dessa magnitude traz várias dificuldades para os atores envolvidos. Os efeitos podem ser percebidos pelas marcas deixadas tanto entre os facilitadores quanto entre os demais participantes. 
Para os facilitadores entrevistados, a implementação da estratégia EPS trouxe sentimentos contraditórios para a equipe:

Pra nós sempre foi um prazer muito grande, apesar de sofrermos, porque tinha dia que a gente chegava tão exausto aqui e falava: 'Não vou mais pra lá, eu não quero mais ser facilitador...', mas, que nada, parece uma cachaça... e, na outra semana, você ia lá e já tava animado de novo, e a gente retomava [...] e aí a gente aplicava as ferramentas e falava: 'Ah não, olha que legal' [...] mas hoje também a gente sabe que, se tivesse acompanhamento aqui, teria sido melhor. Um tipo de supervisão pra nós que saímos como facilitadores [...] (Entrevista Coletiva, Facilitadores).

A alteração do modelo de educação e de acompanhamento do trabalho das UBS e a ausência de um grupo de supervisão/suporte produziram sofrimentos importantes na equipe responsável por acompanhar os espaços de 'rodas' de EPS: “É difícil. A gente tinha que ter tido reuniões aqui dentro pra um dar suporte pro outro [...] pra se ajudar... porque era difícil, uma coisa que nós não estávamos acostumados [...]" (Entrevista coletiva, Facilitadores).

A falta de supervisão ou suporte para atuar como facilitador das 'rodas' foi bastante enfatizada pelo grupo de facilitadores. Alguns apontaram que as 'reuniões de segunda-feira', como chamam o momento de discussão que reúne todo o grupo de facilitadores, se colocavam como um momento de EPS para os próprios facilitadores, mas a maioria referiu que aquele momento não foi bem aproveitado para esse fim, visto que ocupavam o tempo com informes administrativos e planejamento de todas as ações da Gerência: "Eu discordo um pouco porque a reunião de segunda-feira é um espaço de 'roda' [...]" (Entrevista coletiva, Facilitadores); “Eu acho que as nossas reuniões não funcionavam como 'rodas'" (Entrevista coletiva, Facilitadores).

A reflexão dos facilitadores sobre as reuniões faz pensar que o grupo viveu momentos de angústia para realizar sua tarefa na condução das 'rodas' de EPS nas unidades. Obstáculos se ergueram diante da novidade que a proposta representava, diante do enfrentamento das resistências dos trabalhadores, da dificuldade em expressar o não-saber e da ausência de um apoio institucional que oferecesse um espaço de EPS para esse grupo. Como movimento grupal, o tempo das reuniões foi, então, tomado predominantemente por questões administrativas, evitando-se olhar para tais dificuldades, o que nos faz sugerir que o desenvolvimento de habilidades de análise e manejo dos movimentos grupais deveriam ser uma ferramenta fundamental para o trabalho do facilitador de EPS (Fortuna et al., 2005).

Os facilitadores explicitam uma crítica ao curso que não os instrumentalizou para as exigências de manejo para realizar a EPS. O formato do curso, com alguns momentos presenciais e grande parte a distância, parece não ter sido suficiente para colocar os facilitadores em formação em educação per- 
manente, mas demonstrou força estratégica produzindo mobilização de sujeitos para a realização de formas variadas de formação na saúde.

\section{As modalidades de participação nas 'rodas'}

Alguns facilitadores atribuem o sucesso ou insucesso das 'rodas' à presença, grau de participação e engajamento dos diretores que, segundo eles, conferia legitimidade ao processo. Essa constatação dos facilitadores referenda a concepção de que a EPS vai além da formação e converte-se em uma estratégia de gestão dos serviços de saúde.

Foi possível identificar várias modalidades de participação dos trabalhadores nas 'rodas': aqueles que acreditaram e buscaram se envolver nas atividades da UBS, aqueles que participavam pela imposição da gerência e aqueles que aproveitavam o espaço para descansar da sua rotina de trabalho.

Observou-se, também, o lugar de destaque ocupado pelos profissionais de nível superior, diretor e facilitador, bem como a existência de hierarquia na participação dos trabalhadores. Os de nível superior são os que mais se manifestam, são mais ouvidos e se responsabilizam por grande parte das tarefas, ou seja, reproduzem coletivamente as relações de poder/saber no instante vivo da 'roda' em que alguns assumem papéis que lhes são adjudicados (por força da categoria, dos estereótipos, da hierarquia formal, entre outras) e outros delegam. A recorrência à hierarquização das relações foi referida por trabalhadores entrevistados em uma unidade de saúde. Um deles mencionou que "Não se deve falar na reunião, porque depois é repreendido fora da 'roda' pela chefia".

Foi possível constatar, nas 'rodas' de EPS, movimentos típicos da dinâmica grupal, o que aumenta a relevância da habilitação para o manejo dos processos grupais por aqueles que se propõem a essa tarefa. $\mathrm{Na}$ 'roda' presenciada, os participantes se colocavam como que à espera de um 'salvador da pátria', alguém que se responsabilizasse, assumisse e realizasse as tarefas. Diante da contradição expressa pela frase "A gente gosta do projeto, mas não anda com ele", verifica-se o movimento que se dá no sentido de culpar alguém ou transferir a responsabilidade, seguindo um modelo instituído.

A participação dos usuários nos espaços das 'rodas' de EPS tem sido um dos grandes desafios da implementação dessa política. Segundo levantamento realizado pela secretaria de saúde do município, no ano de 2006, apenas 3,5\% do total de 'rodas' de EPS contavam com a participação dos usuários, apontando a necessidade de investigar o motivo de tal afastamento.

Observa-se, na experiência de Vitória, que, apesar do grande esforço em problematizar o processo de trabalho, construir fluxos coletivamente e assim promover uma reflexão sobre a produção de cuidados, o modelo de atenção 
ainda se mantém preso à lógica centrada nas ações médicas. A dificuldade em romper com o modelo hegemônico talvez se deva aos conceitos e valores dos diversos profissionais de saúde, somada à falta de habilidade para trabalhar com grupos e seus movimentos por parte dos facilitadores.

O efeito de capilarização da modalidade da EPS, como espaço de discussão, com o objetivo de organizar os processos de trabalho e melhorar a qualidade do serviço, confirma-se por sua existência mesmo em unidades que não contavam com a ajuda do facilitador para a realização das 'rodas' de EPS. Em uma delas, a gestora local promovia quatro 'rodas' de EPS quinzenalmente.

\section{As 'rodas' de EPS: seu encerramento}

A EPS se faz em meio a tensões diante da diversidade de interesses de gestores, de algumas categorias profissionais e dos desejos e direitos da população. Essa tensão tanto produziu avanços na transformação das práticas em saúde como causou desinteresse e desmobilização do grupo (Merhy, 2002).

A realização de 'rodas' de EPS como estratégia de gestão partilhada e de reflexão sobre o cotidiano de trabalho aconteceu durante três anos e meio. No entanto, parte significativa do contingente de trabalhadores das unidades de saúde em Vitória, naquele período, estava submetida a contrato temporário, o que certamente gerou dispêndio de energia sem resultados:

Ficamos esses anos todos treinando profissionais de contrato de temporário, passado um ano eles iam embora e vinham outros. Felizmente o concurso trouxe muitos de volta. Negócio de contrato temporário não dá certo, na unidade [...] tinham dois ou três funcionários permanentes, os outros eram todos temporários, o gestor tem que ter muita paciência (Facilitadora).

A variedade de efeitos produzidos nesses espaços, os questionamentos e reivindicações direcionados à gestão, a desmobilização e o desgaste do grupo de educadores/facilitadores são elementos que contribuíram significativamente para que a gestão municipal determinasse a extinção das 'rodas' de EPS em meados de 2008.

Na verdade, houve uma interdição para que os facilitadores não continuassem suas atividades nas 'rodas' de EPS. A justificativa para tal decisão foi a necessidade de avaliar a efetividade das "rodas", ao mesmo tempo em que a Semus impulsionava a implantação de outros projetos e estratégias assistenciais e de gestão.

Evidenciam-se, assim, as tensões próprias da gestão do cotidiano em saúde conformando distintos territórios inter-relacionados de disputa: o território da organização dos serviços, expressando tensões do campo da 
disputa de poder entre os atores, da autonomia e controle; o território de configuração de práticas de saúde construído nas disputas de interesses e capacidade de agir, aliando-se ou confrontando-se pela definição de ações que façam sentido e atendam às necessidades, desenhando políticas; e o território de produção de atos de saúde, marcado pela micropolítica do trabalho vivo em ato, pelos autogovernos dos trabalhadores de saúde (Merhy, 2002; Merhy; Feurwerker; Ceccim, 2006).

$\mathrm{Na}$ perspectiva da maioria dos facilitadores que estavam à frente das ações de EPS, a determinação de extinção das 'rodas' foi precipitada e arbitrária: “Houve uma determinação de que agora as 'rodas' de educação permanente não podem mais ter a participação dos facilitadores do GFDS e pronto, acabou" (Entrevista coletiva, Facilitadores).

Muitos questionamentos surgiram sobre o motivo que levou a secretaria de saúde ao encerramento das atividades denominadas 'rodas' de EP. Muitas suposições são mencionadas durante o grupo de discussão com os facilitadores, demonstrando a necessidade de busca de algum sentido para aquela decisão que para eles foi arbitrária: "Essa é a sensação que eu tenho [...] a gente não conseguiu contaminar toda a secretaria [...]" (Entrevista coletiva, Facilitadores).

Alguns mencionam que as 'rodas' incomodavam os diretores, pois elas criavam um movimento de cogestão e muitos deles não se encontravam aptos a exercê-la. Também falam da dificuldade de construir protagonismos de fato:

Era muito difícil o trabalhador se perceber protagonista. O nosso sistema de saúde, historicamente, é construído de uma forma hierarquizada, algumas pessoas elaboram e mandam, outras pessoas obedecem. Isso já está enraizado (Entrevista coletiva, Facilitadores).

Também percebemos que havia uma expectativa geral de que tais facilitadores, de fato, resolvessem os problemas de funcionamento das unidades. De modo geral, as unidades, ou o 'pessoal da ponta', estão acostumadas a ter seus problemas resolvidos pelo 'pessoal do nível central', e essa lógica se manteve com a presença semanal de alguém que, vindo da secretaria, por certo, poderia resolver os 'nossos problemas'. Além disso, transparece nas falas que, de fato, muitos se autoimpuseram essa responsabilidade: "Fomos vistos como nível central. Eu acho que isso ficou no imaginário, de achar que a gente ia pra resolver problema e tal [...] e por vezes, o facilitador acabava ocupando este espaço" (Entrevista coletiva, Facilitadores).

Nesse momento, o grupo reconhece a produção complementar de papéis, reafirmando o modo tradicional de trabalhar em saúde no qual quem resolve é o 'nível central'. Esse relato reflexivo nos aponta que, apesar de todo investimento e dos avanços em EPS no município de Vitória, muito ainda 
teria a ser enfrentado, por exemplo, ser facilitador sem 'fazer por', mobilizando as potencialidades e autonomia das equipes, ou seja, fazendo-se desnecessário para a equipe.

Destacamos que a possibilidade de pensar em potencializar espaços coletivos, com todos os embates e tensões inerentes, deve-se a uma história construída a partir de relações micropolíticas, nas quais técnicos, gestores, instituições de ensino e cidadãos do município se permitiram rever conceitos e práticas, contribuindo, assim, para um processo em construção de um novo modelo de saúde:

Eu acho que foi rico, assim, em relação ao crescimento do grupo, é que a gente cresceu tanto e amadureceu tanto que colocar o trabalho em análise começou a ser uma prática [...]. E o grupo foi se fortalecendo a ponto de estar sempre questionando, revendo, repensando" (Entrevista coletiva, Facilitadores).

Atualmente, vários espaços coletivos de discussão se mantêm, mesmo com diferentes nomenclaturas. Essas iniciativas se devem à mobilização dos trabalhadores e dos coordenadores em manter um espaço de permanente questionamento sobre o processo de trabalho e suas vicissitudes. Sem dúvida, isso denota a incorporação da postura de mudança pelos trabalhadores consolidada na construção coletiva e na grupalidade vivenciada.

\section{Considerações finais}

A organização de um sistema de saúde, assim como a vida, se dá em processo constante de oscilações e flutuações. Reconhecer seu caráter processual é fundamental para identificar o lugar, o momento e as intervenções possíveis. As mudanças são construídas ao longo dos tempos e a ansiedade para que essa transformação ocorra rapidamente, fruto da lógica da instantaneidade do mundo contemporâneo, pode turvar nossa visão e nos impossibilitar de perceber os efeitos micropolíticos que dão suporte às mudanças de paradigma.

Assim, mesmo que as 'rodas' tenham sido encerradas, novos espaços coletivos vêm se constituindo no âmbito da Secretaria de Saúde do Município de Vitória, onde o conhecimento, sensibilidade e prática reflexiva sobre o processo de trabalho acumulados a partir da Educação Permanente em Saúde estarão presentes nos sujeitos das ações de saúde que vivenciaram aprendizagens significativas e vislumbraram novos sentidos para suas práticas.

Entretanto, é preciso atenção e delicadeza com os movimentos coletivos, pois, ao se propor interrupção ou substituição por outros, corre-se o risco de gerar descrédito, ou seja, pode parecer aos trabalhadores que houve apenas uma mudança de nome e que se as 'rodas' de Educação Permanente 
'não funcionaram' e outras modalidades coletivas podem também se converter em atividades sem sentido e ter o mesmo fim.

Há que se valorizar o efeito de capilarização da EPS no município de Vitória, que levou à efetivação de 'rodas' em unidades que não contavam com facilitadores ou apoiadores da secretaria da saúde. É preciso reconhecer que se trata de processo de construção social e operado por um coletivo institucional e assim enfrentar os modos instituídos no âmbito das práticas, das relações hierárquicas, das instâncias de saber e poder e do que se anuncia como limite.

Ressaltamos, no entanto, um aspecto que parece merecer atenção especial: os técnicos são enfáticos quanto ao entendimento de que a forma de compreender a educação e os movimentos de formação foi totalmente alterada por movimentos emanados pela EPS, porém frisam que as questões relativas à cogestão ou à gestão partilhada, também postas em funcionamento pelas 'rodas' de EPS ao se discutir o processo de trabalho, merecem reflexão. O lugar de conhecimento e poder que vem do 'nível central' parece contrastar com o discurso que pretende valorizar iniciativas emanadas do trabalho vivo em ato e do conhecimento acumulado no trabalho pelas equipes e trabalhadores locais.

Dessa forma, sem a discussão sobre esses aspectos micropolíticos, outras experiências de trabalho coletivo, ainda que acrescentem novas formas de abordagem e consigam aumentar a responsabilização dos profissionais, por meio, por exemplo, da construção dos projetos terapêuticos singulares, ou pela pactuação de indicadores regionais, correm o risco de serem obliteradas naquilo que nos parece ser um dos elementos fundamentais da educação permanente: a construção de um sujeito autônomo e criativo.

Outro aspecto que merece destaque e reflexão é a pouca visibilidade e reconhecimento por parte dos gestores de todo o investimento pessoal e afetivo exercido pelos facilitadores para a efetivação das 'rodas' de EPS. Entretanto, a experiência das 'rodas' de educação permanente em saúde faz parte da história da Secretaria Municipal de Saúde de Vitória e o aprendizado acumulado, certamente, não se perderá, uma vez que seus efeitos estarão presentes na produção de novos entrelaçamentos, novas ações, novos disparadores que sustentarão novas formas de produzir saúde. Formas essas que se efetivam no fazer diário dos profissionais que foram transformados nesse processo intenso do fazer saúde e educação. 


\section{Nota do Editor}

Este artigo apresenta parte dos resultados da pesquisa "Avaliação das experiências de Educação Permanente em Saúde, desencadeadas a partir da formação a distância de tutores e facilitadores no Brasil". Edital MCT-CNPq/MSSCTIE-DECIT n²3/2006, Processo CNPq - 409352/2006-3.

\section{Notas}

1 Psicóloga da Secretaria Municipal de Saúde de Vitória, Espírito Santo (SMS/ES) e docente da Faculdade Brasileira (Univix), Vitória, Espírito Santo, Brasil. Mestre em Psicologia pela Universidade Federal do Espírito Santo (Ufes). <elzimarpeixoto@gmail.com> Correspondência: Rua Agenor Amaro dos Santos, 600, Ed. Ilha de Paros, apto. 402, Jardim Camburi, Vitória, Espírito Santo, Brasil, CEP 29090-010.

2 Professora adjunta da Universidade Federal do Espírito Santo (Ufes), Vitória, Espírito Santo, Brasil. Doutora em Psicologia pela Universidade Federal do Espírito Santo (Ufes). $<$ dalbello@intervip.com.br $>$

3 Professora Doutora da Escola de Enfermagem de Ribeirão Preto da Universidade de São Paulo (EERP/USP), Ribeirão Preto, São Paulo, Brasil. Doutora em Enfermagem em Saúde Pública pela Escola de Enfermagem de Ribeirão Preto da Universidade de São Paulo (EERP/USP).<smatumoto@uol.com.br>

4 Professora adjunta da Universidade Federal de São Paulo (Unifesp), Santos, São Paulo, Brasil. Doutora em Ciências Médicas pela Universidade Estadual de Campinas (Unicamp). <angeruma@uol.com.br>

${ }^{5}$ Médica sanitarista da Secretaria de Estado da Saúde de São Paulo, São Paulo, Brasil Especialista em Saude Pública pela Faculdade de Saúde Pública da Universidade de São Paulo (FSP-USP). <mariarosalogiodice@yahoo.com.br>

6 Professora Titular da Escola de Enfermagem de Ribeirão Preto da Universidade de São Paulo (EERP/USP), Ribeirão Preto, São Paulo, Brasil. Doutora em Enfermagem em Saúde Pública pela Universidade de São Paulo (USP). <smishima@eerp.usp.br>

7 É importante destacar que pela natureza da proposta de investigação e do grupo de pesquisadores, que contou com participantes do país como um todo, as análises foram realizadas em Oficinas Metodológicas com a finalidade de ajustar o processo de definição metodológica e de análise dos dados. 


\section{Referências}

BRASIL. Ministério da Saúde. Portaria n. ${ }^{\circ} 198$. Política Nacional de Educação Permanente em Saúde. Brasília, DF: Diário Oficial da União, 13 fev., 2004a.

Ministério da Saúde. Secretaria de Gestão do Trabalho e da Educação na Saúde. Departamento de Gestão da Educação na Saúde. Política de educação e desenvolvimento para o SUS: caminhos para a educação permanente em saúde: polos de educação permanente em saúde. Brasília: Ministério da Saúde, 2004b.

Ministério da Saúde. Secretaria da Gestão do Trabalho e da Educação na Saúde. Ministério da Saúde, Departamento de Gestão da Educação na Saúde. Curso de formação de facilitadores de educação permanente em saúde: orientações para o curso. Rio de Janeiro: Fiocruz, 2005.

Ministério da Saúde. Gabinete do Ministro. Portaria n.o 1996/GM/MS, de 20 de agosto de 2007. Dispõe sobre as diretrizes para a implementação da Política Nacional de Educação Permanente em saúde e dá outras providências. Brasília: MS, 2007.

CARDOSO, Ivana M.; MURAD, Ana L.G; BOF, Sandra M.S. A institucionalização da educação permanente no Programa de Saúde da Família: uma experiência inovadora. Trabalho, Educação e Saúde, Rio de Janeiro, v. 3, n. 2, p. 429-439, 2005.

CECCIM, Ricardo B.; FEUERWERKER, Laura C. M. O quadrilátero da formação para a área da saúde: ensino, gestão, atenção e controle social. Physis: Revista de Saúde Coletiva, Rio de Janeiro, v. 14, n. 1, p. 41-65, 2004.

CECCIM, Ricardo B. Educação permanente em saúde: desafio ambicioso e necessário. Interface: Comunicação, Saúde, Educação, Botucatu, v. 9, n. 16, p. 161-177, 2005.

DALBELLO-ARAUJO, Maristela. Grupo de discussão: facilitadores. Relatório descritivo. Vitória: Ufes/ Semus; 2008b.
Comunidade ampliada de pesquisa. In: ROSA, E. M; SOUZA, L; AVELLAR, L. Z (Org.). Psicologia social: temas em debate. Vitória: Ufes - Abrapso/GM, 2008a. p. 108-126.

DALBELLO-ARAÚJO, Maristela.; PEIXOTO, Elzimar E. Refletindo sobre o trabalho em saúde: aspectos de educação permanente. Relatório final. Curso de Extensão, Proex, Ufes, 2005.

FORTUNA, Cinira M. et al. O trabalho de equipe no programa de saúde da família: reflexões a partir de conceitos do processo grupal e de grupos operativos. Revista Latinoamericana de Enfermagem, Ribeirão Preto, v. 13, n. 2, abr. 2005.

INSTITUTO BRASILEIRO DE GEOGRAFIA E ESTATÍSTICA (IBGE). Cidades@. Disponível em: <www.ibge.gov.br/cidadesat/ default.php>. Acesso em: 8 out. 2009.

KASTRUP, Virginia. O funcionamento da atenção no trabalho do cartógrafo. Psicologia e Sociedade, Porto Alegre, v. 19, n. 1, 2007.

MERHY, Emerson E. Saúde: a cartografia do trabalho vivo. São Paulo: Hucitec, 2002.

MERHY, Emerson E; FEUERWERKER, Laura C.M. CECCIM, Ricardo B. Educación permanente en salud: una estrategia para intervenir en la micropolitica del trabajo en salud. Salud Colectiva, Buenos Aires, v. 2, n. 2, p. 147-160, mayo-agosto 2006.

MOTTA, José Inácio J. Educação permanente em saúde: da política do consenso à construção do dissenso. Dissertação (Mestrado em Educação em Saúde) - Universidade Federal do Rio de Janeiro, 1998.

NICOLETTO, Sonia C.S. et al. Polos de educação permanente em saúde: uma análise da vivência dos atores sociais no norte do Paraná. Interface: Comunicação, Saúde, Educação, Botucatu, v. 13, n. 30, p. 209-219, 2009. 
PASSAMANI, J. D.; ZORZAL-SILVA, M.; DALBELLO-ARAUJO, M. Estratégia saúde da família: o acesso em um território de classe média. Revista de Odontologia, Vitória, Ufes, p. 37-45, 2008.

ROLNIK, Sueli. Cartografia sentimental: transformações contemporâneas do desejo. Porto Alegre: Sulina/UFRGS Editora, 2006.

SANTOS, Boaventura S. Para um novo senso comum: a ciência, o direito e a política na transição paradigmática. In: . A crítica da razão indolente: contra o desperdício da experiência. São Paulo: Cortez, 2000. v. 1.
VITÓRIA. Secretaria Municipal de Saúde. Coordenação de Educação em Saúde, Gerência de Formação e Desenvolvimento em Saúde. Relatório de gestão, Vitória, 2006.

Recebido em 25/02/2010

Aprovado em 26/03/2010 